\title{
Strong Anion Exchange for Studying Protein-DNA Interactions by H/D Exchange Mass Spectrometry
}

\author{
Justin B. Sperry, J. Micah Wilcox, and Michael L. Gross \\ Department of Chemistry, Washington University in St. Louis, St. Louis, Missouri, USA
}

The use of mass spectrometry to study protein-ligand interactions is expanding into more complex systems including protein-DNA interactions. The excess amount of a model DNA or, more typically, an oligodeoxynucleotide (ODN), needed to study such interactions in an amide hydrogen-deuterium (H/D) exchange experiment, for example, causes serious signal suppression in the protein analysis. We describe here a modification of the traditional $\mathrm{H} / \mathrm{D}$ exchange protocol whereby we utilize a strong anion exchange column to rapidly remove the ODN from solution before MS analysis. We showed the successful incorporation of such a column in a study of two protein-ODN systems: (1) the DNA-binding domain of human telomeric repeat binding factor 2 with a telomeric oligodeoxynucleotide and (2) thrombin with the thrombin-binding aptamer. The approach gave no appreciable difference in back-exchange compared to a method in which no strong anion exchange (SAX) is used. (J Am Soc Mass Spectrom 2008, 19, 887-890) (c) 2008 American Society for Mass Spectrometry

$\mathrm{H}$ ydrogen-deuterium (H/D) exchange mass spectrometry (MS) [1] is an emerging tool for studying protein-ligand interactions. Although the final measurement is in the gas phase of a mass spectrometer, $\mathrm{H} / \mathrm{D}$ exchange enables the interactions to be studied under "biologically relevant" solution conditions (i.e., neutral $\mathrm{pH}$, strong buffers, and high ionic strengths) and at relatively low concentrations of protein. The amide exchange is monitored by measuring the mass change of a protein, in either a bound or unbound state, after incubation in deuterated buffer. If amide sites are affected by ligand binding, their exchange rates may decrease in the bound state. Differences are caused by global or local conformational changes associated with ligand binding, formation of protein-ligand interfaces, and/or formation of more stabilized secondary structure elements throughout the protein. Both kinetics of exchange and affinity of the protein can be determined, the latter by either PLIMSTEX (Protein-Ligand Interactions by Mass Spectrometry, Titration, and H/D Exchange) [2] or SUPREX (Stability of Unpurified Proteins from Rates of H/D Exchange) [3].

In many $\mathrm{H} / \mathrm{D}$ exchange protocols, an aqueous protein solution is diluted with deuterated buffer to make an exchange solution high in $\mathrm{D}_{2} \mathrm{O}$ content. After an appropriate exchange time, the reaction is quenched by lowering the $\mathrm{pH}$ to $2-3$ and the temperature to near $0{ }^{\circ} \mathrm{C}$.

Address reprint requests to Prof. Michael L. Gross, Washington University in St. Louis, Department of Chemistry, Campus Box 1134, St. Louis, MO 63130. E-mail: mgross@wustl.edu
The quenched solution is loaded onto a reverse-phase column and washed with chilled water ( $\mathrm{pH} 2-3)$. The wash step removes salts, buffers, and back-exchanges the fast-exchanging deuterated sites. The protein is eluted into the mass spectrometer, where its mass is measured to reveal the extent of deuterium uptake. Ideally the steps from quench to detection are sufficiently rapid (within $3 \mathrm{~min}$ ) to ensure that few deuteria are lost to backexchange.

Although H/D exchange has been successfully applied to many protein-ligand interactions, there are few reports of those involving an oligodeoxynucleotide $(\mathrm{ODN})[4,5]$. While investigating two protein-ODN interactions using electrospray ionization (ESI), we discovered that the protein signal can be entirely suppressed by the presence of an ODN, especially when its concentration exceeds that of the protein by a factor of three or more. Given that ODN:protein ratios greater than 10:1 are required to ensure nearly complete binding, a means of reducing the concentration of the ODN before MS analysis is needed. One possibility is to add ion-exchange chromatography; another is to change to matrix-assisted laser desorption ionization (MALDI), which is less susceptible to signal suppression [4].

Ion-exchange chromatography [6-8] separates species based on their charge in solution. An anion-exchange column should trap ODN anions but minimally affect the protein cations, taking advantage that, under quench conditions, the ODN is anionic and the protein cationic. Here we describe the use of a dual-column approach for H/D exchange of protein-ODN com- 
plexes and test the approach by using two model systems.

\section{Experimental}

\section{Reagents}

The sodium chloride $(\mathrm{NaCl})$ salt, potassium chloride $(\mathrm{KCl})$ salt, HEPES buffer (N-2-hydroxyethylpiperazine- $\mathrm{N}^{\prime}$-2-ethanesulfonic acid and sodium salt), isotopically labeled water $\left(\mathrm{D}_{2} \mathrm{O}, 99.999 \%\right.$ deuterium replacement), formic acid, hydrochloric acid, and acetonitrile reagents were purchased from SigmaAldrich (St. Louis, MO, USA) at the highest purity available and were used without further purification. The $\alpha$-thrombin protein was purchased from Hematologic Technologies Inc. (Essex Junction, VT, USA) as a $167 \mu \mathrm{M}$ solution in $50 \%$ glycerol (aq) and was stored at $-4{ }^{\circ} \mathrm{C}$ upon receipt without further purification. The thrombin-binding aptamer (5'-GGT TGG TGT GGT TGG-3') was purchased from Integrated DNA Technologies (Coralville, IA, USA) as an ammonium salt. This sample was purified by the manufacturer using reverse-phase HPLC to exclude salts as much as possible. The DNA-binding domain of human telomeric repeat factor 2 (hTRF2) was prepared as described previously [5]. The model of telomeric DNA (5'-GTT AGG GTT AGG G-3') and its complement were also purchased from Integrated DNA Technologies, analyzed by mass spectrometry for purity, and used without further purification.

\section{Model System}

Thrombin interaction. The master solution of the thrombin-binding aptamer was prepared by dissolving weighed amounts of solid sample in deionized water. The master protein solution was prepared by diluting the solution received from the manufacturer with HEPES buffer solution. The concentrations of these master solutions were determined by UV absorption spectrophotometry; for each sample, a calibration plot was prepared to give the molar absorptivity. For the aptamer, the experimentally determined value agreed to within $1 \%$ of the value calculated by the nearestneighbor method for the given sequence and agreed with the molar absorptivity reported by the manufacturer. For the protein, the experimentally determined value agreed to within $5 \%$ of the value reported by the manufacturer. The "working master" apothrombin solution was $2.5 \mu \mathrm{M}$ in $10 \mathrm{mM}$ HEPES, $\mathrm{pH} 6.8$, and contained $25 \mathrm{mM} \mathrm{NaCl}$ and $0.8 \%$ glycerol (vol/vol), whereas the "working master" holo solution was 2.5 $\mu \mathrm{M}$ thrombin and $25 \mu \mathrm{M}$ thrombin-binding aptamer in $10 \mathrm{mM}$ HEPES, $\mathrm{pH}$ 6.8, containing $25 \mathrm{mM} \mathrm{NaCl}$ and $0.8 \%$ glycerol ( $\mathrm{vol} / \mathrm{vol})$.

Human TRF2 interaction. Double-stranded telomeric DNA was prepared by mixing equimolar amounts of the complementary, single-stranded ODNs in a $10 \mathrm{mM}$ HEPES buffer containing $150 \mathrm{mM} \mathrm{KCl}$. Duplex formation was monitored by UV absorption spectrophotometry $(260 \mathrm{~nm})$ by decreasing the solution temperature from 95 to $25^{\circ} \mathrm{C}$ by $5^{\circ} \mathrm{C}$ increments every $30 \mathrm{~min}$. The apo protein stock solution was prepared so that it contained $41 \mu \mathrm{M}$ hTRF2 in $10 \mathrm{mM}$ HEPES (pH 7.4) and $150 \mathrm{mM} \mathrm{KCl}$. The holo protein stock solution was prepared so that it contained $41 \mu \mathrm{M}$ protein and $410 \mu \mathrm{M}$ telomeric DNA in $10 \mathrm{mM}$ HEPES (pH 7.4) and $150 \mathrm{mM}$ $\mathrm{KCl}$. The preparation of these samples was discussed previously [5].

\section{Mass Spectrometry}

Mass spectra were acquired using a quadrupole-time of flight (Q-ToF) Ultima mass spectrometer (Waters, Milford, MA, USA), equipped with an ESI source and operated in the positive-ion mode. The instrument conditions were optimized for each protein analyzed; briefly, the capillary voltage was $3.0-3.2 \mathrm{kV}$, the conevoltage readback was $100-105 \mathrm{~V}$, the cone-gas flow rate was $40 \mathrm{~L} / \mathrm{h}$, the desolvation gas flow rate was $400 \mathrm{~L} / \mathrm{h}$, the source temperature was $80^{\circ} \mathrm{C}$, and the desolvation temperature was $180^{\circ} \mathrm{C}$. The MS profile used for quadrupole transmission was: from $\mathrm{m} / \mathrm{z} 500$, dwell for $5 \%$ of the scan time, ramp to $m / z 1000$ for $45 \%$ of the scan time, then dwell at $\mathrm{m} / z 1000$ for the remaining $50 \%$ of the scan time. The scan time for the instrument was $2 \mathrm{~s}$. The protein-ODN solution was passed through the strong anion exchange $(\mathrm{SAX})$ column $(1 \times 15 \mathrm{~mm}$ OPTI-GUARD, Optimize Technologies Inc., Oregon City, OR, USA), to trap the ODN, and then onto a $\mathrm{C}_{8}$ reverse-phase guard column $(1 \times 15 \mathrm{~mm}$ OPTIGUARD), pre-equilibrated with $0.2 \%$ formic acid in water, to trap the protein. The reverse-phase column was washed with $300 \mu \mathrm{L}$ of $0.2 \%$ formic acid in water $\left(0{ }^{\circ} \mathrm{C}\right)$ and eluted using an isocratic flow of $30 \%$ solvent B (hTRF2) or $50 \%$ solvent B (thrombin) at $40 \mu \mathrm{L} / \mathrm{min}$ by a Waters CapLC. The HPLC solvents were (solvent A) $94.7 \%$ deionized water, $5 \%$ acetonitrile, and $0.3 \%$ formic acid and (solvent B) $94.7 \%$ acetonitrile, 5\% deionized water, and $0.3 \%$ formic acid.

\section{Results and Discussion}

To minimize ionization suppression effects of an oligodeoxynucleotide (ODN) in protein studies, we considered capturing the protein on a reverse-phase column and washing away the ODN. Although such gradient elution may be successful, its use increases the experimental time and, consequently, the extent of back-exchange. Further, a gradient elution approach would not be amenable for studies in which the deuterated protein is proteolyzed to gain higher resolution data because retention of the peptides formed in proteoloysis and ODN will be similar, thus creating the potential for peptide-signal suppression. These disad- 
vantages prompted us to consider including a strong anion exchange (SAX) column to remove the ODN.

In the modified procedure, we placed the SAX column in the flow path after the syringe injection port and in front of the injection valve (see Figure 1). At the start of an experiment, the injection valve was in LOAD for injection of the protein-ODN mixture with a standard syringe. The solution passed sequentially through the SAX column, the injection loop, the reverse-phase column (typically $\mathrm{C}_{8}$ ), and finally through the waste port of the valve. Because the quenched solution's $\mathrm{pH}$ is $2-3$, the protein remains positively charged, whereas the ODN is negative. Therefore, the ODN adheres to the SAX column while the protein passes on and is trapped on the reversephase column. Having separated the ODN and protein molecules, the protein is washed with chilled water $(\mathrm{pH}$ 2-3) and eluted isocratically into the mass spectrometer by switching the injector valve to INJECT. While in this mode, the ODN was eluted from the SAX column with $300 \mu \mathrm{L}$ of aqueous $\mathrm{NaOH}(\mathrm{pH} 9-10)$.

One model system to test the effectiveness of strong anion exchange involves the $7.5 \mathrm{kDa}$ DNA-binding domain of the hTRF2 that interacts with a double-stranded telomeric ODN [5]. The second model is the thrombinthrombin binding aptamer where a $36 \mathrm{kDa}$ protein interacts with a single-stranded DNA aptamer that is folded into a non-canonical quadruplex structure [9].

The mass spectrum (Figure 2a) is of 10 pmol of hTRF2 injected onto a $C_{8}$ column and eluted into the mass spectrometer without the use of a SAX column. That in Figure $2 b$, however, is of 10 pmol of hTRF2 with 100 pmol of telomeric ODN injected onto and eluted from a $\mathrm{C}_{8}$ column without the use of a SAX column. This 10:1 ratio ensured nearly complete binding of the protein in solution. We observed no protein ions resulting from excessive ion suppression from the ODN. Observed instead are the positive ions of the C-rich strand of telomeric DNA (the ion at $m / z 956.7$ is the +4 charge state and the ion at $m / z 1275.3$ is the +3$)$. When we incorporated the SAX column and injected the same 10:1 sample, we found a significant increase in the protein signal and no ions from the ODN (Figure 2c). The relative intensity of the protein signal in Figure 2c is $10-15 \%$ that of Figure $2 a$.

Turning to the second model, the control is a mass spectrum (Figure 2d) of $10 \mathrm{pmol}$ of thrombin loaded onto a $\mathrm{C}_{8}$ column and eluted into the mass spectrometer without a SAX column. That in Figure 2e, 10 pmol of thrombin and $100 \mathrm{pmol}$ of its ODN ligand loaded onto a $\mathrm{C}_{8}$ column and eluted without a SAX column, shows the dramatic signal suppression of the ODN. The ions shown in Figure 2e are of the ODN ligand (the ion of $\mathrm{m} / \mathrm{z} 977.9$ is the +5 charge state and the ion of $\mathrm{m} / \mathrm{z} 1221.9$ is the +4 charge state). The salutary effect of incorporating a SAX column for the analysis of the 10:1 sample solution (Figure 2f) is revealed by an increase in the relative abundance of the protein signal, which is $10-15 \%$ of the relative abundance of the protein signal in Figure 2d.
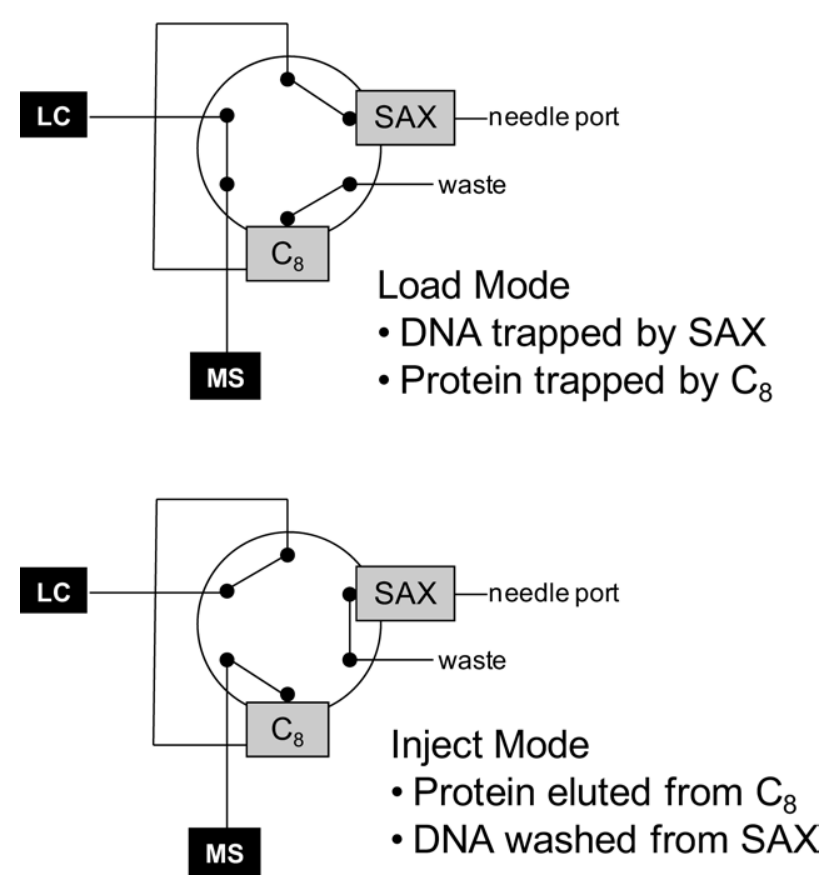

Figure 1. Diagram of the dual-column setup in the load and inject mode.

In the modified procedure, the time from quench to detection is not increased so it is unlikely that backexchange is increased by inclusion of the SAX column. To test our hypothesis, we measured the extent of D uptake for a 1:1 mixture of hTRF2 and its ligand (double-stranded telomeric DNA) in the presence and absence of a SAX column. In this experiment, the protein-ODN mixture was incubated in deuterated buffer $\left(97 \% \mathrm{D}_{2} \mathrm{O}\right)$ for $10 \mathrm{~min}$, quenched, loaded onto the $\mathrm{C}_{8}$ column (with and without SAX), washed, and eluted into the mass spectrometer. For triplicate experiments, the average uptake without SAX was $53.2 \pm 0.9 \mathrm{Da}$, whereas with SAX, the average was $53.7 \pm 0.9 \mathrm{Da}$. Clearly, the presence of the SAX column does not affect the extent of back-exchange.

\section{Conclusion}

In summary, the application of H/D exchange to proteinODN interactions requires decreasing the amount of signal suppression caused when the ODN coelutes with the protein into the ESI mass spectrometer. The simple incorporation of a SAX column into the experimental protocol enables trapping the ODN while passing most of the protein onto a reverse-phase column and into the ion source without increasing the extent of back-exchange. Although we do not report here the outcome and interpretation of the H/D exchange data, we can state that this modified approach worked for two protein-ODN systems: a TRF2 interaction, where the H/D exchange results were recently reported [5]; and a thrombin interaction, where the H/D exchange study is the focus of current work. 
(a)

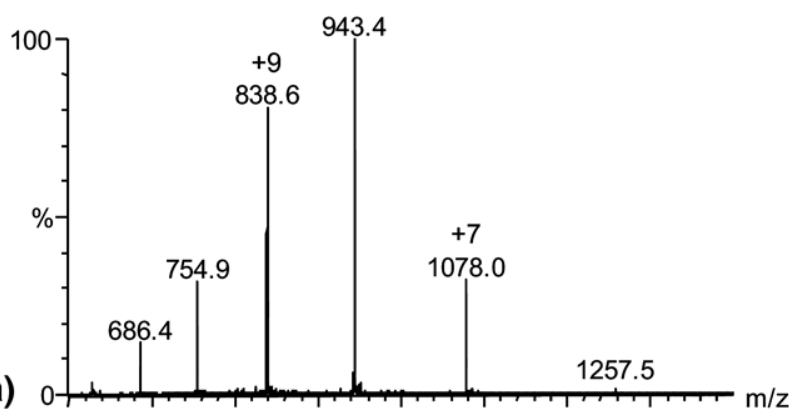

(b)

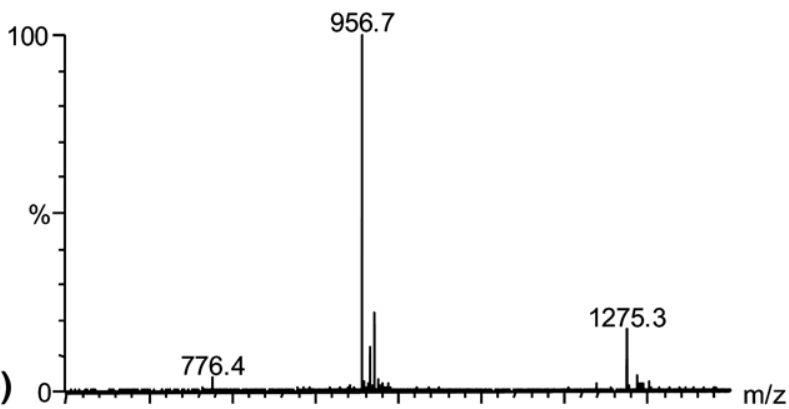

(c)

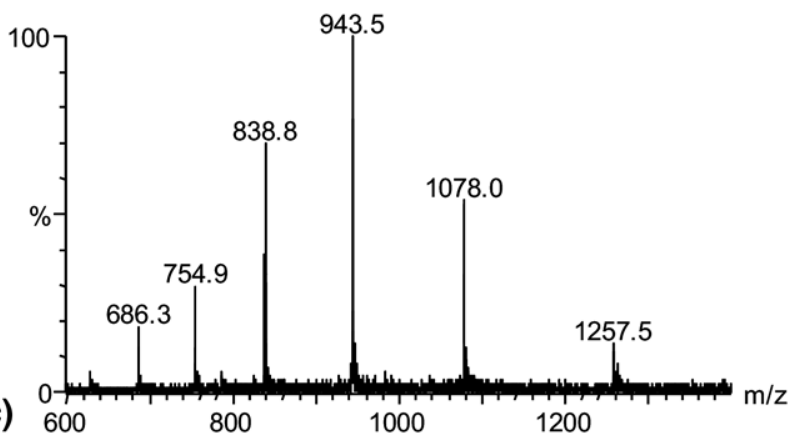

(d)

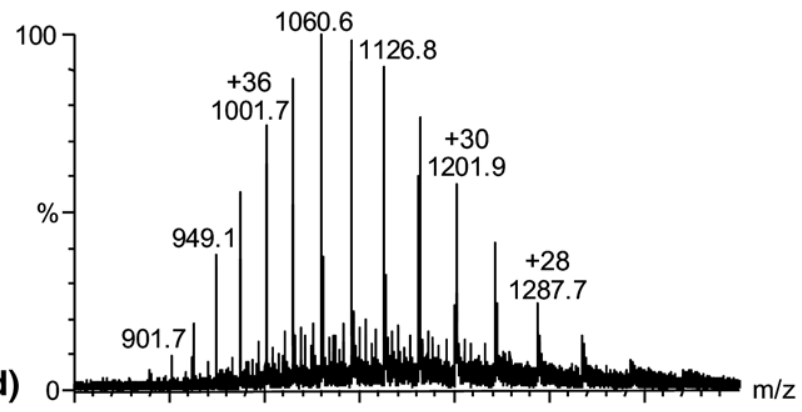

(e)
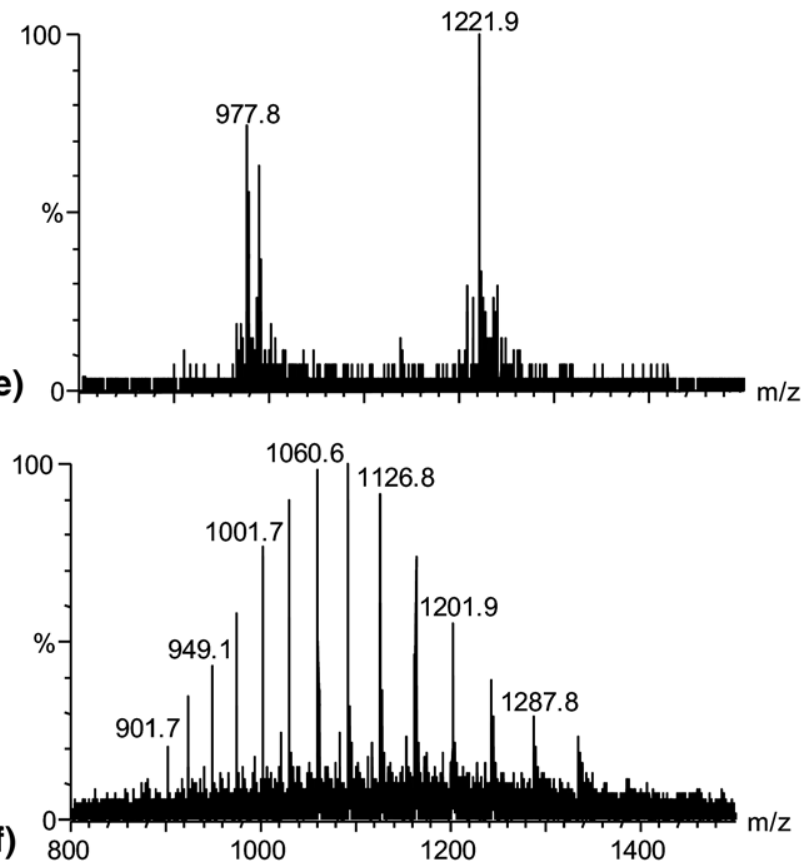

Figure 2. Mass spectra from two model systems. (a) 10 pmol hTRF2 without SAX column present, (b) 10 pmol hTRF2 and 100 pmol telomeric DNA without SAX column present, (c) 10 pmol hTRF2 and 100 pmol telomeric DNA with SAX column present, (d) 10 pmol thrombin without SAX column present, (e) $10 \mathrm{pmol}$ thrombin and $100 \mathrm{pmol}$ thrombin-binding aptamer without SAX column present, and (f) 10 pmol thrombin and 100 pmol thrombin-binding aptamer with SAX column present.

\section{Acknowledgments}

These studies were supported by the National Institutes of Health and National Center for Research Resources (Grant P41RR000954). We thank S. Akashi and Y. Nishimura, Yokohama City University, Japan, for a generous gift of the human TRF2 DNA-binding domain protein.

\section{References}

1. Wales, T. E.; Engen, J. R. Hydrogen Exchange Mass Spectrometry for the Analysis of Protein Dynamics. Mass Spectrom. Rev. 2006, 25 , $158-170$.

2. Zhu, M. M.; Rempel, D. L.; Du, Z.; Gross, M. L. Quantification of Protein-Ligand Interactions by Mass Spectrometry, Titration, and H/D Exchange: PLIMSTEX. J. Am. Chem. Soc. 2003, 125, 5252-5253.
3. Ghaemmaghami, S.; Fitzgerald, M. C. A Quantitative, High-throughput Screen for Protein Stability. Proc. Natl. Acad. Sci. U.S.A. 2000, 97, 8296-8301.

4. Ma, L.; Fitzgerald, M. C. A New H/D Exchange- and Mass SpectrometryBased Method for Thermodynamic Analysis of Protein-DNA Interactions. Chem. Biol. 2003, 10, 1205-1213.

5. Sperry, J. B.; Shi, X.; Rempel, D. L.; Nishimura, Y.; Akashi, S.; Gross, M. L. A Mass Spectrometric Approach to the Study of DNA-Binding Proteins: Interaction of Human TRF2 with Telomeric DNA. Biochemistry 2008, 47, 1797-1807.

6. Green, G. D. J.; Prior, C. P. Method Using Anion Exchange Resin for Removing DNA from Protein Preparations. World Intellectual Property Organization Patent WO/1990/008159.

7. Willis, T. C.; Goldberg, B. A Model System for DNA Removal from Protein Solutions. Am. Biotechnol. Lab. 1992, 10, 24.

8. Fritz, J. S.; Gjerde, D. T. Ion Chromatography, 3rd edition; Wiley-VCH: Weinheim, Germany, 2000.

9. Padmanabhan, K.; Padmanabhan, K. P.; Ferrara, J. D.; Sadler, J. E.; Tulinsky, A. The Structure of $\alpha$-Thrombin Is Inhibited by a 15-mer Single-stranded DNA Aptamer. J. Biol. Chem. 1993, 268, 17651-17654. 